\title{
A comunicação humana a partir de Vilém Flusser: uma leitura do fenômeno comunicacional na pós-história
}

Human communication from Vilém Flusser: a reading of the communicational phenomenon in post-history

\author{
Draiton de Souza Gonzaga* \\ Jair Inácio Tauchen*
}

\begin{abstract}
Resumo: No começo dos anos de 1990, a informática já era uma realidade nos países desenvolvidos, tema que provocou muito interesse na nova geração de designers, intelectuais e artistas, entusiasmados com os avanços das novas tecnologias. É essencialmente nesse cenário que Flusser foi reconhecido como um teórico inovador das novas mídias. O objetivo do trabalho é discutir a comunicação humana no pensamento de Vilém Flusser, sobretudo a do período maduro das suas convicções teóricas, a partir das conferências de Bochum, onde se debateu a problemática da comunicação humana e do livro Comunicologia publicado primeiramente na Alemanha. O ser humano parece ser o único fenômeno capaz de produzir informações deliberadamente, capaz de transmitir e guardar informações, não apenas as herdadas, mas também as adquiridas. Por conseguinte, a fundamentação dos argumentos será dividida em três tópicos: o armazenamento das informações adquiridas, o processamento e a transmissão das informações.
\end{abstract}

Palavras-chave: comunicação humana; armazenamento; processamento; transmissão.

\begin{abstract}
At the beginning of the nineties, informatics was already a reality in developed countries, sparking much interest in a new generation of designers, intellectuals and artists, who were excited by the advancement of new technologies. Within this scenery, Flusser was recognized as a groundbreaking thinker of the new media. The aim of our work is to discuss the human communication in the thought of Vilém Flusser, with special reference to the mature period of his theoretical convictions. We will take our bearings from Bochum's Conferences (1991), where the problem of human communication was debated, and from the book Kommunikologie, first published in Germany in 1998. The human being seems to be the only phenomenon capable of producing information in an intentional way, as well as of transmitting and stocking pieces of information - not just inherited information, but also acquired information. As a consequence, the justification of our argument will be divided into three topics: the stocking of acquired information, the processing, and the transmission of information.
\end{abstract}

Keywors: Human communication; storage; processing; transmission.

\footnotetext{
* Professor Titular de Filosofia na PUCRS. Doutor em Filosofia pela Universidade de Kassel/Alemanha. Contato: draiton@pucrs.br
}

* Doutorando em Filosofia PUCRS. Contato: jairtauchen@gmail.com 


\section{Introdução}

O ano de 1991 foi duplamente marcante na vida de Flusser. No semestre de verão desse ano foi convidado pela Universidade do RuhrBochum para lecionar como professor convidado. O local não poderia ser mais sugestivo, um galpão rural reformado e decorado com artefatos camponeses, com um auditório disposto a escutá-lo falar da pós-história e da utilização da informática no processo da comunicação humana. Na sua visão, o homem processa, armazena e transmite algo que lhe é próprio: a língua, a cultura, a informação. O segundo momento foi no outono do mesmo ano, depois da fuga dos nazistas, ao retornar pela primeira vez à Praga, sua cidade natal, onde veio a falecer num acidente de carro. Foi como uma previsão: naquele galpão, diante dos jovens alunos e professores, enquanto discorria sobre a intenção de apresentar sua crítica da cultura frente às novas mídias e de desenvolver uma futura comunicologia, afirmou que aceitou o convite, por assim dizer, "no apagar das luzes, antes de bater as botas."

No começo dos anos de 1990, a informática já era uma realidade nos países desenvolvidos, tema que provocou bastante interesse na nova geração de designers, intelectuais e artistas, todos entusiasmados com os avanços das novas tecnologias. É essencialmente nesse cenário que Flusser foi reconhecido como um teórico inovador das novas mídias; inclusive para registrar suas conferências em Bochum, sobre a problemática da comunicação humana, solicitou que fosse gravado em áudio, tendo a clara intenção de chamar atenção sobre o tema e antecipar para os universitários as novas tendências das tecnologias da rede de informação.

Diante deste horizonte que se apresentava a Flusser, sobretudo aquele que irrigou o período maduro de suas convicções teóricas, a intenção deste artigo consiste em discutir a comunicação no pensamento do autor, especialmente a partir do livro Comunicologia, publicado primeiramente na Alemanha. Portanto, parece natural partir da pergunta: o que é comunicação humana? Na concepção do filósofo "trata-se de armazenar informações adquiridas, processá-las e transmiti-las”. ${ }^{2}$ Tal

\footnotetext{
${ }^{1}$ FLUSSER, Vilém. Comunicologia: reflexões sobre o futuro: as conferências de Bochum. São Paulo: Martins Fontes, 2014, p. 35 .

${ }^{2}$ FLUSSER, Vilém. Comunicologia: reflexões sobre o futuro: as conferências de Bochum. São Paulo: Martins Fontes, 2014, p. 33 .
} 
capacidade também é reservada a outros organismos vivos da natureza. No entanto, o homem parece ser o único fenômeno capaz de produzir informações deliberadamente e, do mesmo modo, capaz de transmitir e guardar informações não apenas as herdadas, mas também as adquiridas. Esse argumento implica variáveis, considerando que a teoria da comunicação humana ocupa posição de destaque na atualidade. Desse modo, o esforço da argumentação estará centrado em abordar três tópicos relacionados entre si: o armazenamento das informações adquiridas, o processamento e a transmissão das informações, com ênfase nas tecnologias de comunicação, sobretudo a internet, possivelmente o processo mais revolucionário da comunicação global.

\section{A comunicação humana: decorrência do armazenamento, processamento e transmissão das informações adquiridas}

No período da hominização, quando o homo erectus andava pelo mundo, ao pegar uma pedra qualquer e transformá-la em objeto, elegeu um problema. Isso nunca havia acontecido, extrair algo do mundo da vida, do mundo objetivo, e transformá-lo em artefato. Essa ação provocou um estranhamento, a hominização de um lado e o mundo objetivo do outro. Com a evolução do homo sapiens, para armazenar as informações adquiridas, utilizou-se do seguinte método: o primeiro foi a emissão de sons, algo que faz parte da própria genética e, também, comum a outros vertebrados, pois são dotados de órgãos que permitem tal possibilidade, como por exemplo, emitir um som cujo significado represente perigo. "A capacidade de falar é hereditária, mas as formas como as ondas de ar são transformadas em fonemas são uma informação adquirida."3 Não existe uma língua natural; a língua precisa sempre ser "renovadamente adquirida". Justamente uma das desvantagens da "cultura oral" é que parte das informações se perdem na transmissão. É por isso que para os humanos as informações adquiridas são mais relevantes que as herdadas.

A comunicação humana é um processo artificial que está baseado em mecanismos, ferramentas, instrumentos, ou seja, em símbolos que depois de organizados tornam-se códigos. Um sistema codificado como

\footnotetext{
${ }^{3}$ FLUSSER, Vilém. Comunicologia: reflexões sobre o futuro: as conferências de Bochum. São Paulo: Martins Fontes,
} 2014 , p. 52. 
um fenômeno possível de ser interpretado, embora o sentido artificial aludido na comunicação humana nem sempre é totalmente consciente. Depois de aprender determinado código, a tendência é esquecer sua artificialidade, como por exemplo, o gesto de balançar a cabeça indicando "sim", os sinais de trânsito, os móveis. Flusser entende que o homem se comunica com os outros, é um "animal político", "não pelo fato de ser um animal social, mas sim porque é um animal solitário, incapaz de viver na solidão." $\mathrm{O}$ que Flusser quer dizer é que o mundo codificado em que o homem vive, consiste num sistema artificial que esconde uma natureza sem significado e sem sentido e, em função desse contexto, o objetivo é fazer esquecer que se encontra sozinho, enfrentar a ausência de sentido inerente à sua condição de solidão, e tornar a vida visível.

A comunicação humana pode ser encarada pelo ponto de vista da existência, uma tentativa de superar a morte através da companhia dos outros, ou do ponto de vista formal, ao envolver a produção e o armazenamento da informação. Ou seja, uma comunicação que se estabelece a partir dos símbolos ordenados com o propósito de represar as informações, ou quando as informações são trocadas através do diálogo na esperança de gerar novas informações. O que é possível detectar nesses pontos de vista é que as duas formas de comunicação estão entrelaçadas, isto é, uma depende da outra para existir.

Diante de todos os artifícios disponíveis, nunca dantes na história a comunicação funcionou de forma tão intensiva e extensiva como na atualidade. A grande dificuldade reside na qualidade dos diálogos, pois a troca de informação implica novas informações. Muitas dessas informações são transmitidas com ruídos, de difícil compreensão, ou sem efetividade.

A primeira parte da definição enfatiza que o objetivo da comunicação é armazenar informações. Todavia, não é qualquer informação, mas as informações adquiridas. A cultura passa a ser um meio para transmitir essas informações enquanto resultado do armazenamento e da possibilidade de acesso que podem ser modificadas ao longo da história.

Entre as denominações utilizadas para identificar a espécie humana - homo sapiens sapiens e homo faber -, a segunda apresenta um caráter mais antropológico do que zoológico porque indica que o homem pertence à espécie que fabrica algo. A fabricação, manipulação de artefatos é uma

\footnotetext{
${ }^{4}$ FLUSSER, Vilém. O mundo codificado: por uma filosofia do design e da comunicação. São Paulo: Cosac Naify, 2007, p. 91.
} 
característica desenvolvida pela espécie humana. Sobre essa questão, Flusser insiste em afirmar que os homens podem ser reconhecidos por suas fábricas. ${ }^{5}$ Uma maneira de investigar como o homem vivia, pensava, sentia, é examinar, por exemplo, a produção de cerâmicas do período neolítico. Essa análise é válida também para os períodos históricos posteriores até a contemporaneidade, ou até mesmo para reconhecer o homem do futuro nas fábricas do futuro.

A história da humanidade observada pelo viés da fabricação indica, segundo Flusser, quatro períodos distintos: "o das mãos, o das ferramentas, o das máquinas e o dos aparelhos eletrônicos (Apparate)." ${ }^{6}$ Na sequência apresenta o sentido de fabricar: "fabricar significa apoderarse (entwenden) de algo dado na natureza, convertê-lo (umwenden) em algo manufaturado, dar-lhe uma aplicabilidade (anwenden) e utilizá-lo (verwenden)". O importante a ser destacado nessa dinâmica é que cada vez mais as informações herdadas tornam-se menos importantes, ao contrário das informações adquiridas, pois os aparelhos eletrônicos exigem uma aprendizagem mais abstrata.

O resultado desse movimento é a transformação do homem em um sujeito artificial, alienado do mundo, aprisionado pela cultura e que aos poucos vai perdendo seu sentido natural. É o que Flusser chama de "contra-ataque das máquinas" em função até mesmo da alteração do comportamento humano, como por exemplo, ao afirmar que "os jovens dançam como robôs, os políticos tomam decisões de acordo com cenários computadorizados, os cientistas pensam digitalmente e os artistas desenham com máquinas de plotagem." " Esse fenômeno é decorrente do fato de que na atualidade, cada vez mais a maioria dos aparelhos são construídos por "máquinas inteligentes" e o homem passa a intervir no processo apenas eventualmente.

A memória, por sua vez, é a encarregada de armazenar as informações adquiridas no processo da comunicação humana. O diálogo é um meio pelo qual utiliza as informações armazenadas em duas ou mais memórias a fim de produzir uma troca e, por consequência, lançar novas informações. Quando ocorre a troca de informações entre duas memórias

\footnotetext{
${ }^{5}$ FLUSSER, Vilém. O mundo codificado: por uma filosofia do design e da comunicação. São Paulo: Cosac Naify, 2007, p. 35.

${ }^{6}$ FLUSSER, Vilém. O mundo codificado: por uma filosofia do design e da comunicação. São Paulo: Cosac Naify, 2007, p. 36.

${ }^{7}$ FLUSSER, Vilém. O mundo codificado: por uma filosofia do design e da comunicação. São Paulo: Cosac Naify, 2007, p. 49.
} 
que se aproximam muito, o diálogo torna-se supérfluo porque não produz nada de novo. Por exemplo, o diálogo coloquial de duas pessoas que se encontram na rua para falar do tempo, se vai chover ou não, do ponto de vista da informação não acontece nada. Por outro lado, informações totalmente diferentes entre duas memórias não permitem o diálogo. É o caso da utilização de duas línguas distantes, por exemplo, a tentativa de diálogo de alguém que fala tcheco e outro que fala português, a comunicação apenas provoca ruído, não produz troca de informação.

O método utilizado para transmitir as informações armazenadas na memória é o discurso: "o diálogo produz informações, o discurso as mantém”, esclarece Flusser. Para o processo da comunicação humana ser exitoso, é fundamental que o discurso e o diálogo estejam sintonizados. Se porventura prevalecer o diálogo, sobrevém um distanciamento entre as pessoas devido a falta da informação; é o caso do nascimento das elites, um exemplo próprio da atualidade. Por outro lado, quando o discurso prevalece, advém o empobrecimento da cultura e a corrosão das informações, como foi na época do nazismo e do stalinismo. Para Flusser, o difícil equilíbrio entre diálogo e discurso apenas é passível de ser conquistado através dos aparelhos. ${ }^{9}$

O ser humano vive no mundo objetivo, condicionado por todos os lados a resolver problemas utilizando objetos. Desde aproximadamente sessenta mil anos, quando o homo sapiens sapiens entrou em cena, está continuamente solucionando problemas. Conseguiu sair rastejando do mundo objetivo para a condição de duplamente sábio. O desafio ao se deparar com os objetos sempre foi de superá-los, empregando a técnica como método. O homem se tornou sujeito dos objetos e ao manipulá-los, armazena informações, passando a olhar o mundo a partir dessa subjetividade abstraída. Os objetos não são mais objetivos, são fenômenos e para orientar-se no mundo, fixa a subjetividade numa parede de caverna utilizando tinta. ${ }^{10}$ Esse processo permite simbolizar a ideia, a partir de uma abstração, abreviada através da visão em código, no caso, um mamute. $\mathrm{O}$ código serve de referência para que outros também tenham condições de

\footnotetext{
${ }^{8}$ FLUSSER, Vilém. Comunicologia: reflexões sobre o futuro: as conferências de Bochum. São Paulo: Martins Fontes, 2014, p. 5 o.

${ }^{9}$ FLUSSER, Vilém. Comunicologia: reflexões sobre o futuro: as conferências de Bochum. São Paulo: Martins Fontes, 2014, p. 51 .

${ }^{10}$ As cavernas em Lascaux e Pechemerle, são exemplos.
} 
decifrar. Esse processo é denominado de imaginação. Para Flusser, a criação de uma imagem decorre do "rastejar para dentro de si mesmo, de lá olhar para fora, fixar o que foi avistado, usar uma parede de pedra como apoio de memória e, assim, fixar o avistado, para que outros possam decifrá-lo." ${ }^{11}$ Com isso, ele quer dizer que as imagens são para o pintor o resultado final da sua intenção.

A pintura na caverna resultou numa imagem, uma representação que todos podem ver, porque a sua função é representar objetos. Elas servem de orientação para o mundo objetivo; são como mapas que indicam o caminho para uma mudança de vida. No pensamento de Flusser, "as imagens representam (vorstellen) os objetos, e assim, elas se apresentam diante (stellen sich vor) dos objetos." ${ }^{12}$ A imagem é uma superfície sobre a qual foi aplicada alguma informação, por isso serve como depositária da informação. No exemplo das imagens na caverna em Lascaux, elas foram tão bem armazenadas que, após milhares de anos, ainda estão legíveis, são possíveis de decodificar.

Pode ocorrer uma inversão no processo de orientação pelas imagens, ou seja, em vez do homem se orientar no mundo objetivo com o auxílio de uma imagem, passa a se orientar na imagem com a ajuda do mundo objetivo. Na história isso tem nome: para o judaísmo é chamado de adoração de imagens, paganismo, idolatria, fazendo sentido a orientação bíblica: "não deves fazer imagens". No pensamento de Flusser, esse processo corresponde a uma tripla alienação: "primeiro, estou alienado da vida por meio dos objetos, depois estou alienado dos objetos por meio das imagens e agora eu mesmo estou alienado das imagens." ${ }^{13} \mathrm{O}$ mundo representado pelas imagens, tornou-se alucinação, ou seja, a cultura material da imagem é cada vez mais mágica e o mundo oral mítico. Para combater e sintetizar esse processo mítico e mágico, é necessária uma nova consciência que se desenvolve na cultura escrita histórica.

\footnotetext{
${ }^{11}$ FLUSSER, Vilém. Filosofia da caixa preta: ensaios para uma futura filosofia da fotografia. São Paulo: Annablume, 2011, p. 125 .

${ }^{12}$ FLUSSER, Vilém. Filosofia da caixa preta: ensaios para uma futura filosofia da fotografia. São Paulo: Annablume, 2011, p. 127.

${ }^{13}$ FLUSSER, Vilém. Filosofia da caixa preta: ensaios para uma futura filosofia da fotografia. São Paulo: Annablume, 2011, p. 129.
} 
A consciência histórica, segundo Flusser ${ }^{14}$, é consequência do surgimento da escrita e que se revela no ato de escrever. As representações dos elementos das imagens foram dilaceradas, rasgadas para torná-las transparentes para o mundo dos objetos na forma de sinais. A função da escrita linear é libertar o homem de todos os mitos, de todas as magias para torná-lo um ser que pensa e age historicamente. As imagens são contadas pelo texto, no entanto, a migração para esse processo foi lento e gradual porque, muitas vezes, os textos ainda estavam carregados de imagens, transformando o pensamento histórico em imaginativo. A justificativa de Flusser sobre a transição é de que "a dialética texto-imagem é um pensamento imaginativo progressivo na história e um pensamento conceitual progressivo na imagem." ${ }^{15}$

É de amplo conhecimento que durante o período histórico da Idade Média, a Igreja, através dos seus membros, assumiu o protagonismo da escrita. Somente a classe dominante era alfabetizada, a grande parte das pessoas que viviam nas cidades e nos campos, permaneciam analfabetas. As pessoas eram informadas pelos monges, mas não conseguiam decifrar as informações, tendo que aceitar sem crítica o conhecimento dos detentores do poder.

Atualmente, a história se repete e a situação é a mesma. Uma elite comanda os modelos de conhecimentos e de vivência, utilizando códigos matemáticos e outros programas computadorizados praticamente impossíveis de decifrar. Somente uma casta de especialistas consegue dominá-los. O que se percebe em decorrência disso, é que personalidades importantes, como por exemplo, presidentes de países e políticos, têm diminuídos seu poder de decisão. Quem toma as decisões reais são os analistas em sistemas, especialistas em informática e cientistas que conseguem operar os códigos.

$\mathrm{Na}$ antiguidade os livros, encadernados em couro, contendo informação escrita, sempre tiveram valor como objeto, de tal forma que um mosteiro que tivesse dez livros era considerado importante no século XIII. Graças a Gutemberg ocorreu uma grande transformação, não apenas porque os livros perderam valor em função da facilidade de acesso, mas

\footnotetext{
${ }^{14}$ FLUSSER, Vilém. Filosofia da caixa preta: ensaios para uma futura filosofia da fotografia. São Paulo: Annablume, 2011, p. 130.

${ }^{15}$ FLUSSER, Vilém. Filosofia da caixa preta: ensaios para uma futura filosofia da fotografia. São Paulo: Annablume, 2011, p. 137.
} 
fundamentalmente porque se descobriu que o valor do livro não está no material, no objeto, mas na informação que contém. Apenas o texto dá sentido e valor ao livro e ao leitor do livro.

A impressão do livro, além de romper com a hegemonia dos monges, permitiu antecipar a Revolução Industrial, o Renascimento e a ciência moderna. As pessoas podiam comprar livros, aprender a ler e a escrever, produzindo seus próprios modelos de conhecimento. Era possível criar livros, além dos que contavam a história divina, mas sobretudo os que ensinavam uma profissão. A informação ficou acessível às pessoas, não sendo mais necessário o deslocamento até o mosteiro, pois já era possível aprender nas escolas. A transferência do conhecimento dos mosteiros para as escolas da cidade, pode ser considerada um importante movimento para que a escola servisse de meio para o desenvolvimento da técnica, da política e da arte. A consciência histórica, resultado do aprendizado da leitura e da escrita, cuja finalidade foi combater a magia e o mito por meio das explicações utilizando um código, não pertence mais a uma classe dominante de filósofos e monges, mas se transformou em bem universal.

Com o advento da ciência, as pessoas começaram a aplicar os seus conhecimentos. A construção de máquinas foi, por exemplo, algo que transformou a relação do homem com a ferramenta. No princípio, a pessoa permanecia em sua oficina rodeada de ferramentas para realizar o seu ofício. Nessa fase, Flusser entende que a pessoa "era a constante, a ferramenta, a variável ${ }^{16}$ ”, porque, quando uma ferramenta quebrava, trocava-se por uma nova, enquanto o artesão permanecia na oficina. No entanto, com o surgimento da técnica houve uma inversão. Construíram prédios para abrigar as máquinas e recrutaram pessoas no campo para trabalhar, mas agora em função das máquinas. Isso fez com que a máquina significasse a constante e o operário, a variável, porque se instituiu um mercado de trabalho no qual foi permitido, caso um operário ficasse doente ou morresse, que fosse substituído por outro operário, semelhante ao estágio anterior, o das ferramentas.

No centro do interesse estava a máquina que produzia e as pessoas trabalhavam em função das máquinas. Esse sistema de produção é conhecido por sociedade industrial, que Flusser entende como uma das

\footnotetext{
${ }^{16}$ FLUSSER, Vilém. Filosofia da caixa preta: ensaios para uma futura filosofia da fotografia. São Paulo: Annablume, 2011, p. 142.
} 
situações mais insanas da história da humanidade: "não basta que as pessoas exerçam funções, com efeito, elas também têm de consumir aquilo que sai das máquinas, senão a máquina para. De dia alimenta a máquina e à noite têm de engolir o que sai da máquina." ${ }^{17}$

Quando as pessoas foram recrutadas no campo para manejar as máquinas nas indústrias, para entender as instruções de uso e para operálas, houve a necessidade de aprender a ler e a escrever ${ }^{18}$, especialmente nos países chamados desenvolvidos. Fica evidente que o trabalho não é mais a única fonte de valores, mas também a informação. Segundo Flusser, foi necessário instituir três níveis escolares diferentes para atender a nova demanda. As escolas primárias para ensinar as pessoas a operar as máquinas; as escolas secundárias para aprender a fazer a manutenção e o conserto das máquinas; as escolas superiores para a criação de novas máquinas e mais eficientes. $\mathrm{O}$ valor sobrevém da informação adquirida, que não é material, pois pode ser transferida de um lugar para outro, ou na exemplificação de Flusser, "o valor do bolo está na receita." ${ }^{19} \mathrm{O}$ processo do trabalho passa a estar centrado na elaboração da informação (ciência) e na gravação da informação (técnica). A técnica consiste em manipular as coisas de tal maneira que elas adquirem as consequências que se busca.

\section{A evolução comunicativa da pré-história, história e pós-história}

A história caminha a passos rápidos, a consciência histórica produz um número cada vez maior de acontecimentos ${ }^{20}$, algo que Baudelaire já havia percebido ao presenciar a primeira câmera fotográfica, aparelho que consente registrar algo a partir do fluxo histórico. O acontecimento serve de

\footnotetext{
${ }^{17}$ FLUSSER, Vilém. Filosofia da caixa preta: ensaios para uma futura filosofia da fotografia. São Paulo: Annablume, 2011, p. 143.

${ }^{18}$ Flusser entende que as escolas, no primeiro momento, foram criadas para atender os interesses das máquinas, uma posição um tanto polêmica, quando se discute que a obrigatoriedade e frequência escolar são fatores que contribuíram para o aumento do nível da educação da população através de um processo democrático e universal (FLUSSER, 2014, p. 144). Outro fator a ser considerado é que a escola passa a assumir uma posição central na vida das pessoas, pois até aproximadamente os 25 anos de vida, nos países ocidentais desenvolvidos, a pessoa vai à escola ou a escola vai até ela.

${ }^{19}$ FLUSSER, Vilém. Filosofia da caixa preta: ensaios para uma futura filosofia da fotografia. São Paulo: Annablume, 2011, p. 185 .

${ }^{20}$ Aqui, Flusser utiliza um jogo de palavras entre História e Acontecimento bem observado pelo tradutor. "O substantivo Geschichte (História) provém do verbo geschehen (acontecer). Portanto, o termo alemão para "História" significa literalmente "acontecimento", em sentido geral, e não episódico (FLUSSER, 2014, p. 211).
} 
pretexto para as imagens, elas desejam ser programadas. O que é registrado pela máquina, produto de uma fórmula histórica, fica retido, eternizado na fotografia, especialmente as imagens digitais inventadas no século XX. A imagem é uma informação que revela o instante sobre uma superfície e, para decifrar a mensagem, o olhar circula ao redor da imagem, que é fixa, caracterizando um tempo de eterna repetição, ou como Flusser denomina inúmeras vezes, um tempo pré-histórico. A imagem não se move, está ordenada em seu lugar e no tempo. O contrário é o filme onde as coisas se movem, um movimento mágico que provoca a desordem, ou seja, uma parte da história, que é transformado em uma cena. A fotografia é um processo da consciência pós-histórica, pois quem vê uma fotografia, vê o que aconteceu, é real, isso no primeiro momento porque entre a fotografia e a coisa a ser fotografada existe um aparelho carregado de combinações técnicas e simbolismos, fazendo com que a fotografia seja subjetiva como qualquer outra imagem. Diferente do pintor tradicional que sabe que a cena na imagem foi produzida por ele, o fotógrafo quando encena uma imagem, apenas intervém nela, é fruto da técnica.

O fotógrafo quando decide por um ponto de vista, significa que teve de recusar todas as alternativas, exceto uma. Nunca saberá se a decisão foi correta, para isso teria que experimentar todas as possibilidades, o que não é possível fazer. Esse processo está condicionado à liberdade de decisão do fotógrafo. Por sua vez, o computador ao efetuar um cálculo, esgota todas as possibilidades até decidir por um resultado. No entanto, essa decisão não é existencial e por isso não é possível falar em liberdade. Isso, na atualidade, denomina-se de inteligência artificial, obra da técnica.

Por exemplo, as fotografias podem ser manipuladas dialogicamente (impressas em folhas), enquanto todas as imagens técnicas são programadas (necessitam de aparelhos). Uma pintura em um quadro é original, no sentido de ser peça única, não é multiplicável e o seu valor é estabelecido enquanto quadro. A sua distribuição é realizada de proprietário a proprietário. A fotografia é reproduzível. Para distribui-la é necessário primeiro multiplicála, motivo pelo qual perde a originalidade. Enquanto valor como objeto é praticamente nulo, porque o valor está na informação que transmite. Para Flusser, a fotografia é um exemplo de objeto pós-industrial, pois “o valor se transferiu do objeto para a informação. Pós-indústria é precisamente isso: 
desejar informação e não mais objetos." ${ }^{21}$ A comparação da fotografia com o quadro, também serve como oportunidade para se pensar nos valores econômicos, éticos e estéticos do passado.

A fotografia é produto do aparelho fotográfico que também é produto de outro aparelho. Os aparelhos podem ser industriais, administrativos, políticos, econômicos. Todo aparelho é alimentado por outro aparelho, que se programam mutuamente. Uma produção humana complexa do século XIX e XX em desenvolvimento, objetivando descobrir novas intenções humanas, para levar à construção de novos aparelhos. Flusser alerta para o fato de que atualmente os aparelhos "obedecem às decisões de seus proprietários e alienam a sociedade. Quem afirmar que não há intenção dos proprietários por trás dos aparelhos, está sendo vítima dessa alienação e colabora objetivamente com os proprietários dos aparelhos.”22 O que quer destacar é que na invenção dos aparelhos estão contidos os interesses dos detentores do poder, denominados de proprietários.

A revolução da comunicação que atinge nossa consciência e nosso ambiente é radical. O sentido de morar, ter casa como a dez mil anos atrás, não existe mais, não faz mais sentido. O vento da comunicação sopra através das paredes levando junto tudo o que é público e privado. Quando se fala do desaparecimento do espaço público, se quer dizer desaparecimento do diálogo, da opinião pública. As estruturas da sociedade como a família, sindicato, classes, também começam a desaparecer.

O propósito das mídias é criar e misturar conteúdos propositalmente para que as mensagens surjam como modelos de vida, que na verdade se transformam em modelos de comportamento, pois as pessoas se comportam de acordo com esses modelos, como por exemplo, nas escolhas políticas, na educação dos filhos. Encobertos pelos modelos de comportamentos, estão os modelos de conhecimento que permitem acesso ao saber, graças aos programas. Agora, se todas as pessoas são abordadas pelos mesmos programas e, por isso, igualmente programadas, não existe diálogo, troca de ideia, pois a mensagem emitida foi a mesma para todos. Outra situação, claramente presente na atualidade, é a inflação de informações, seguido do contínuo aparecimento de novos aparelhos e

\footnotetext{
${ }^{21}$ FLUSSER, Vilém. Filosofia da caixa preta: ensaios para uma futura filosofia da fotografia. São Paulo: Annablume, 2011, p. 64 .

${ }^{22}$ FLUSSER, Vilém. Filosofia da caixa preta: ensaios para uma futura filosofia da fotografia. São Paulo: Annablume, 2011, p. 89 .
} 
a brevidade da validade das informações. Isso compromete a comunicação humana, cuja função é receber informações, armazená-las e transmiti-las, porque para processar uma informação é necessária uma estratificação das informações recebidas e nessa circunstância pós-histórica não existe estratificação, o que compromete sobremaneira o processamento e a elaboração de nova informação.

Numa das conferências de Flusser no Kornhaus", "Reflexões nômades”, expôs a evolução da vivência humana através do argumento de que o homem vivenciou três grandes catástrofes ao longo da sua história, considerando a percepção do espaço e da ocupação do mundo. A primeira foi a hominização ocorrida em função da utilização e manejo da ferramenta de pedra. Como nômade, persegue sua caça como o vento e ao andar, apreende o mundo. A segunda foi a civilização decorrente da sua sedentarização; constrói casas, domestica, cria animais, começa a possuir coisas. Decorrente disso, permanece fixo em determinado lugar, não apreendendo mais o mundo. Nesse período, também desenvolve as imagens tradicionais e a escrita, que substituem o mundo e seus caminhos. A terceira catástrofe está em andamento e ainda não tem nome, é caracterizada pela volta do nomadismo, no qual as casas se tornaram inabitáveis, porque em todos os buracos entra o vento da informação. As imagens técnicas continuamente transmitidas pelas tomadas da eletricidade invadem todos os espaços. É importante ressaltar que nesse novo estilo de nomadismo não é mais o corpo que se desloca e caminha, mas o espírito.

Na primeira catástrofe o homem vivia a caminhar no espaço e tempo, enquanto a caça era sua referência móvel. Na segunda, mantinha uma residência fixa, possuía terras e coisas. Na terceira, o nomadismo é favorecido pelo vento da informação e dos valores simbólicos. O vento que Flusser está se referindo é o sopro do espírito não visível, da imaterialidade que caracteriza as imagens técnicas. O que se percebe é que a cada degrau ocorreu uma redução até o surgimento das não coisas, cujo tema foi tratado por Flusser em 1989 por meio do artigo “A caminho das não coisas”.

\footnotetext{
${ }^{23}$ Os chamados Internationale Kornhaus Seminare (Seminários Internacionais do Celeiro) foram organizados por Harry Pross, em uma pequena aldeia de Weiler, nos alpes alemães de 1984 a 1993. Os debates, sempre calorosos, ocorriam em um celeiro de aproximadamente 200 anos, com duração de uma semana, no qual pessoas como Abraham Moles, Lev Kopelev, Vicente Romano, Carlos Mongardini, Vilém Flusser, discutiam e pensavam a comunicação, a mídia, suas projeções e rumos. O público participante era de umas 150 pessoas e eram convidados importantes jornalistas alemães. Ao total foram 10 seminários. Flusser participou de 8 até 1991, ano em que veio a falecer.
} 
A história da imagem se constrói de abstração de degrau a degrau. No princípio, o entorno do homem era composto por objetos. A partir do momento em que começou a registrar suas marcas na construção de objetos e nas representações imagéticas nas paredes das cavernas, ocorreu uma revolução. As imagens permitiram um novo olhar, uma nova percepção do tempo, denominado por Flusser de tempo circular que admite ao observador retornar sempre ao ponto inicial, um período mágico de eterno retorno. No entanto, a dimensão da profundidade que dá a materialidade da coisa, se perdeu nas imagens planas, nas representações imagéticas sobre as superfícies.

O próximo degrau foi quando as imagens foram transformadas em representações lineares (pictogramas, ideogramas, letras), por ocasião do surgimento da escrita e da leitura. Em vez do olhar ser circular sobre a imagem, passou a seguir uma linha. Mais uma dimensão espacial se perdeu com a invenção da escrita, o tempo foi linearizado, permitindo o aparecimento do tempo histórico. É possível descrever o mundo através do pensamento lógico e linear. O desenvolvimento da ciência e da técnica auxiliaram a criação das máquinas que, por sua vez, ajudaram na tarefa da aquisição e distribuição da escrita.

O pensamento linear e conceitual também criou condições para o surgimento dos aparelhos, responsáveis pelas imagens técnicas. As tecnoimagens são diferentes das imagens tradicionais, pois são resultado da etapa seguinte no degrau da abstração, são formadas por cálculos, fórmulas, projetadas sobre um suporte qualquer. Embora sejam diferentes, as tecnoimagens passam a sensação de imagem tradicional, da circularidade do olhar, operando da mesma forma mágica. Para Baitello Júnior, "as tecnoimagens não são mais uma superfície, mas a construção conceitual de um plano por meio da constelação de grânulos, de pontos de dimensão desprezível, mas que, reunidos, oferecem a ilusão de uma superfície, um mosaico de pedrinhas." ${ }^{24}$

Este último degrau tem consequência direta na vida das pessoas, porque as coisas (toda matéria bruta) perderam valor, enquanto as não coisas (símbolos, software, fama) ganharam importância e valor. É um novo mundo no qual somente o sopro da imaterialidade - que caracteriza

\footnotetext{
${ }^{24}$ BAITELLO JUNIOR, Norval. A serpente, a maçã e o holograma: esboços para uma teoria da mídia. São Paulo: Paulus, 2010, p. 54
} 
as imagens técnicas - tem espaço. O mundo das não coisas desafia a humanidade ao desmaterializar a existência, transformando-a em cálculos, pontos e números. O universo todo está composto de coisas e, até pouco tempo atrás, o valor estava depositado nas casas, móveis, veículos, máquinas. Viver em um mundo de coisas tornava a tarefa mais fácil, pois era possível estabelecer uma relação sobre como proceder para poder viver. Inclusive o ser humano também foi convertido em objeto pela ciência, tornando-se como as demais coisas, admissível de ser calculado, mensurado e possível de manipular.

Houve uma mudança de rumo e atualmente as não coisas (informações) estão invadindo todos os espaços, ultrapassando as coisas. No entanto, Flusser alerta que as informações sempre estiveram presentes, pois todas as coisas contêm informações, como por exemplo, livros, latas de conservas, cigarros. A informação se torna clara quando é possível decifrá-la. O tipo de informação que está em discussão e que invade constantemente o mundo é algo que até então não existia: "são as informações imateriais (undingliche Informationen)." ${ }^{25}$ Trata-se das imagens eletrônicas da televisão, os dados contidos no computador, os hologramas, os programas, todos “impalpáveis”, mas possíveis de serem decodificados.

A base material (as coisas - hardware) está com o preço em declínio, cada vez mais barato e cada vez menor em tamanho, enquanto que as não coisas (informações - software), cada vez mais valorizados. O que se percebe é um deslocamento de interesse das coisas para a informação, uma cultura imaterial. A produção industrial das coisas tende a ficar em segundo plano, enquanto uma parcela maior da sociedade se dedica à produção de informações. Flusser tem a visão de que a classe trabalhadora, ou seja, "os produtores de coisas, está se tornando minoria, enquanto os funcionários e os apparatchiks, esses produtores de não coisas, tornam-se maioria." ${ }^{26} \mathrm{~A}$ tendência é que as coisas percam o seu valor e que sejam transferidas para as informações. Já é possível perceber esse movimento sem precedentes na história, quando países ou grupos financeiros que dispõem de informações privilegiadas (armas atômicas, engenharia genética, farmacêutica, aviação,

\footnotetext{
${ }^{25}$ FLUSSER, Vilém. O mundo codificado: por uma filosofia do design e da comunicação. São Paulo: Cosac Naify, 2007, p. 54 .

${ }^{26}$ FLUSSER, Vilém. O mundo codificado: por uma filosofia do design e da comunicação. São Paulo: Cosac Naify, 2007, p. 55 .
} 
sistemas informáticos...), dominam e exploram cobrando preços altíssimos, subjugando a humanidade.

A questão a saber é: como se comportará o novo homem que se ocupará de símbolos, códigos, sistemas? Como será a sua vida nesse ambiente imaterial? Não deverá ser tarefa fácil, ponderando que não lidará mais com as coisas, isso implicará o desenvolvimento de suas ações concretas em seu trabalho. O trabalho será realizado pela ponta dos dedos, digitando símbolos no teclado. Flusser não tem dúvida de que o "novo homem não é mais uma pessoa de ações concretas, mas sim um performer (Spieler): homo ludens, e não homo faber. Para ele a vida deixou de ser um drama e passou a ser um espetáculo. Não se trata mais de ações, e sim de sensações." ${ }^{27} \mathrm{O}$ certo é que a invasão das não coisas provocará uma guinada radical na existência humana. Não é possível ver claramente, ainda está invisível, mas a humanidade caminha para um totalitarismo programador, uma sociedade composta de programadores e programados.

Assim como num ritual de magia no qual os símbolos passam a operar o homem, em vez do homem operar os símbolos, conclui o programa da terceira catástrofe que, para Flusser, está em curso, sem nome e tornando as casas inabitáveis.

Flusser faz uma análise do sufixo "mática" ${ }^{28}$, cujo significado abrange que qualquer tipo de escravidão, de poder, e da política pode ser transferido para as máquinas. A função do homem seria politizar as máquinas e elas ficariam encarregadas de fazer a política, de fazer guerras, de pagar impostos. No entanto, alerta que infelizmente a palavra "automatização" encerra a palavra "autonomia" que, por sua vez, significa "achar um lugar por si só". Com isso, um autômato pode vir a se tornar um autônomo, cujo significado é "corre por si mesmo, por inércia". Pensadores antitécnicos encaram com preocupação o fato de colocar uma máquina em movimento que funciona por inércia, cujo motor da máquina é o ser humano, entendendo que o ser humano estaria perdendo o controle da situação.

O problema não são as máquinas se tornarem autônomas. Flusser não tem nada contra as máquinas, inclusive acredita que "são, sim,

\footnotetext{
${ }^{27}$ FLUSSER, Vilém. O mundo codificado: por uma filosofia do design e da comunicação. São Paulo: Cosac Naify, 2007, p. 58 .

${ }^{28}$ FLUSSER, Vilém. Comunicologia: reflexões sobre o futuro: as conferências de Bochum. São Paulo: Martins Fontes, 2014 , p. 318
} 
escravas." ${ }^{29}$ Que elas continuem a trabalhar com rapidez e eficiência conforme foram planejadas. O problema real são as pessoas que estão envolvidas com as máquinas, os funcionários que estão perdendo a condição de seres humanos e é urgente retirá-los dessa condição. O mesmo ocorre quando o homem é dominado pelo aparelho burocrático, cujo trabalho consiste numa repetição contínua de tarefas, tornando-se um homem-software. Para ilustrar, Flusser apresenta o exemplo do funcionário, cuja função é emitir passaporte mediante a apresentação de documentos. Sua vida está condicionada a permanecer atrás do balcão manipulando símbolos e sua carreira depende da eficiência de como manipula esses símbolos. Ele recebe os papéis, confere e emite o passaporte. Antes, porém, cola a fotografia e preenche as instruções até estar tudo na mais perfeita ordem. Quando entrega o passaporte, olha para fora pela abertura e compara a fotografia com quem está lá fora. Isso inverte a ordem das coisas, pois "isso não significa que o passaporte seja um símbolo para o ser humano, mas o contrário, que o ser humano é um símbolo para o passaporte.”30 O real é o passaporte e o que está fora, o ser humano, o símbolo. O homem como sujeito do processo não apenas se torna seu objeto, como transfere ao programa do aparelho todo o seu poder, abrindo mão de seu próprio corpo. É imperioso questionar esses cenários, considerar os impactos positivos e negativos a fim de devolver a dignidade aos seres humanos, enquanto ainda é possível, alerta Flusser, "já que $75 \%$ da humanidade atual funciona, em vez de viver, já que 75\% do mundo chamado desenvolvido faz carreira em vez de adquirir informações, ele funciona." ${ }^{11}$ No entanto, para Flusser, a massa não quer essa mudança, ela funciona em função dos símbolos (dinheiro, papel, imagens) e assim quer permanecer.

Uma sociedade telemática, para Flusser, "é uma sociedade em que tudo aquilo que pode ser automatizado está automatizado e todo o resto é ‘tele.”" ${ }^{2}$ O prefixo "tele" (télos) tem a ver com meta que é o processo de

\footnotetext{
${ }^{29}$ FLUSSER, Vilém. Comunicologia: reflexões sobre o futuro: as conferências de Bochum. São Paulo: Martins Fontes, 2014, p. 319.

${ }^{30}$ FLUSSER, Vilém. Comunicologia: reflexões sobre o futuro: as conferências de Bochum. São Paulo: Martins Fontes, 2014 , p. 320.

${ }^{31}$ FLUSSER, Vilém. Comunicologia: reflexões sobre o futuro: as conferências de Bochum. São Paulo: Martins Fontes, 2014 , p. 320.

${ }^{32}$ FLUSSER, Vilém. Comunicologia: reflexões sobre o futuro: as conferências de Bochum. São Paulo: Martins Fontes, 2014, p. 321.
} 
trazer alguma coisa que está longe para perto, mas não no sentido geográfico ou histórico. Como exemplo de "teleinstrumento", é o telescópio, primeiro passo para compreender o significado de telemática, cuja intenção é trazer o que está longe para perto, ou no caso do microscópio, trazer o pequeno para perto. Todos os aparelhos que começam com o prefixo "tele" têm um significado semelhante, como por exemplo, o telefone, televisão, telégrafo. É importante salientar, o que agora é trazido para perto não são apenas objetos, mas também pessoas, colocadas lado a lado, unidas por meio de cabos. Tornar as pessoas próximas através da conexão pela internet é a essência da rede.

\section{Comunicação humana e a revolução tecnológica}

A revolução tecnológica contemporânea se difundiu justamente num período histórico da restruturação do capitalismo no mundo, especialmente a partir de 1980, tornando-se decisivo. O processamento da informação é centrado na ampliação do desenvolvimento tecnológico, como resultado da produtividade, num círculo que abrange o intercâmbio entre as bases do conhecimento tecnológico. Todo avanço em algum campo específico da tecnologia, amplia os efeitos em outros processos tecnológicos. O conjunto de todas essas tecnologias de comunicação levou à criação da internet, possivelmente o meio tecnológico mais revolucionário do mundo contemporâneo.

Diante do exposto, torna-se oportuno perguntar: é possível considerar pessoas ou países que permanecem desconectados da rede de internet, como excluídos ou marginalizados? As novas tecnologias da informação, através das redes globais de instrumentalidade, estão integrando o crescente número de comunidades virtuais. Por outro lado, a questão é saber como integrar novas tecnologias, a ciência universal e as culturas comunitárias na tendência oposta do distanciamento provocado pela globalização e a identidade das pessoas.

$\mathrm{Na}$ atualidade, o que se percebe em determinadas áreas da atividade econômica e política é uma enorme centralidade no uso da informação através da internet. Para os indivíduos que não têm ou possuem um limitado acesso à internet, permanecem à margem, distanciados dos benefícios ofertados pela rede. Ao mesmo tempo em que se exige um maior desempenho na produtividade e na comunicação, percebe-se, por 
outro lado, a exclusão provocada pela desigualdade de possibilidade no acesso à internet. Portanto, a impossibilidade do ingresso à rede amplia o processo de desigualdade social comprometendo o desenvolvimento de uma grande parcela da população. O desafio é encontrar condições necessárias a fim de incluir esses marginalizados na agenda das oportunidades, pois essas desigualdades sociais interferem no âmbito do desenvolvimento global, dos países e das regiões.

Nos países em via de desenvolvimento um dos problemas relativos à desigualdade no acesso à internet está na infraestrutura de telecomunicação que segue uma lenta e ineficiente modernização, muitas vezes dependente de privatização e regulamentação. O papel do Estado na relação entre tecnologia e sociedade, seja promovendo, interrompendo o fluxo ou liderando inovações tecnológicas, tem fator decisivo no processo, porque possui a capacidade de organizar as forças sociais de um país e de uma época. Agora, as novas tecnologias não determinam a sociedade, mas acabam incorporando-a. Por outro lado, a sociedade não determina a inovação tecnológica, mas se utiliza dela. Diante disso, Castells mantem uma relativa cautela ao afirmar que a internet é "uma tecnologia da liberdade, mas pode servir para libertar os poderosos e oprimir os desinformados e pode conduzir à exclusão dos desvalorizados pelos conquistadores do valor". ${ }^{33}$ É evidente que apenas o acesso à rede não é requisito para superar todas as desigualdades numa sociedade cada vez mais conectada, cujos sistemas políticos e econômicos estão cada vez mais organizados em relação à internet.

O surgimento da internet gerou oportunidades nunca dantes imaginadas nos meios de comunicação e informação. No entanto, as exigências para sua utilização geraram um novo problema: a exclusão digital. As diferenças sociais provocadas pela dificuldade de acesso à internet podem estar relacionadas a diversos fatores. Castells ${ }^{34}$ entende que podem estar vinculadas ao salário, à condição étnica, ao status familiar, à educação, tendo como base a pesquisa desenvolvida nos EUA, o país que demonstra clara vantagem sobre os demais. O fato é que a exclusão atinge sobretudo a camada

\footnotetext{
33 CASTELLS, Manuel. A galáxia internet - Reflexões sobre Internet, Negócios e Sociedade. Fundação Calouste Gulbenkian. Lisboa: 2004, p, 317.

34 CASTELLS, Manuel. A galáxia internet - Reflexões sobre Internet, Negócios e Sociedade. Fundação Calouste Gulbenkian. Lisboa: 2004, p, 288-296.
} 
mais pobre e discriminada da população, aumentando ainda mais o hiato da marginalidade e desigualdade social e cultural.

Por outro lado, nos últimos anos os preços dos computadores caíram, favorecendo a aquisição do computador pessoal para os indivíduos de baixa renda. Outros fatores que também contribuíram para aceder à internet foram os equipamentos móveis, as escolas, as bibliotecas, o trabalho, ao permitirem o acesso à rede, potencializando oportunidades às minorias. Ainda assim, percebe-se um elitismo cultural e uma valorização comercial da internet, beneficiando setores prósperos da sociedade ocidental. O sistema econômico mundial no qual a internet é referencial, contribui para o desenvolvimento desigual ao aumentar simultaneamente a riqueza e a pobreza nas diferentes partes do mundo.

A comunicação, já expresso anteriormente, é a essência da atividade humana e a internet é o novo instrumento que pode estabelecer mudanças na estrutura social. Castells entende que a internet, "não é apenas uma tecnologia: é o instrumento tecnológico e a forma organizativa que distribui o poder da informação, a geração de conhecimento e a capacidade de ligar-se em rede em qualquer âmbito da atividade humana." ${ }^{35}$ No entanto, historicamente, toda mudança provoca medo no ser humano e o desafio diante da realidade tecnológica é encontrar determinadas garantias de proteção social.

Tendo em vista que a internet é uma rede que facilita uma comunicação global, de muitos para muitos, a preocupação está na condição de garantir a liberdade para os indivíduos. A apreensão é justificada no sentido de que a infraestrutura da qual a internet depende para permitir o acesso é uma propriedade que pode ser controlada e influenciada por interesses econômicos, políticos e ideológicos. Não obstante, a liberdade na internet está diretamente relacionada à sua comercialização. Como garantir a ausência dessas influências no controle do acesso à rede?

Outro desafio numa economia global e numa sociedade conectada é o problema gerado pela exclusão dos indivíduos, cuja consequência de estar desconectado equivale à marginalidade. A exclusão pode se dar pela ineficiente infraestrutura tecnológica, questões econômicas, educacional e cultural. O resultado da exclusão é a divisão desigual dos indivíduos que

\footnotetext{
35 CASTELLS, Manuel. A galáxia internet - Reflexões sobre Internet, Negócios e Sociedade. Fundação Calouste Gulbenkian. Lisboa: 2004, p,311.
} 
estão conectados à rede e a geração de valor e os que não estão permanecendo em desvantagem no processo global.

Também é desafiador a necessidade de processar a informação disponibilizada transformando-a em ganho de conhecimento, sobretudo na educação das crianças e jovens. Nesse sentido, Castells chama atenção para a mudança na capacidade intelectual "para aprender a aprender durante toda a vida, obtendo informação armazenada digitalmente, recombinando-a e utilizando-a para produzir conhecimentos para o objetivo desejado em cada momento." ${ }^{6}$ Essa proposta envolve a reestruturação de todo o sistema educacional. Poucos países estão aptos para aplicar isso, pois envolve uma pedagogia interativa que permita o desenvolvimento da capacidade de aprender a pensar, diferente do sistema educativo tradicional.

\section{Conclusão}

Portanto, é de fundamental importância levar a sério as mudanças introduzidas pelas transformações tecnológicas e econômicas, centradas na tecnologia da informação que produzem impactos e interferem nas relações entre os indivíduos da sociedade, marcados por mudanças confusas e incontroladas pelas inovações tecnológicas. As alterações na vida social tornaram-se mais explícitas no final do século XX, adquirindo novo sentido realidades como as observadas na arquitetura, na telefonia, na internet, nas operações financeiras do mercado internacional. A sociedade contemporânea encontra-se globalizada, marcada por processos complexos de redes interligadas que comandam a riqueza global, o poder, a informação e a imagem. Por isso, é importante conhecer adequadamente o processo a fim de que a ação humana seja responsável, pois a maneira de lidar com as novas tecnologias, de forma hábil ou não, especialmente aquelas que fazem parte do período histórico, podem provocar as transformações sociais. É imperioso que a sociedade humana encontre uma nova identidade social através de uma racionalidade, mas sem idolatrar sua deusa.

\footnotetext{
${ }^{36}$ CASTELLS, Manuel. A galáxia internet - Reflexões sobre Internet, Negócios e Sociedade. Fundação Calouste Gulbenkian. Lisboa: 2004, p. 320.
} 
514 | Veritas | Porto Alegre, v. 63, n. 2, maio-ago. 2018, p. 493-514

\section{Referências}

BAITELLO JUNIOR, Norval. A serpente, a maçã e o holograma: esboços para uma teoria da mídia. São Paulo: Paulus, 2010.

- A era da iconofagia: reflexões sobre a imagem, comunicação, mídia e cultura. São Paulo: Paulus, 2014.

CASTELLS, Manuel. A sociedade em rede. A era da informação: economia, sociedade e cultura; V.1. São Paulo: Paz e Terra, 1999.

CASTELLS, Manuel. A galáxia internet - Reflexões sobre Internet, Negócios e Sociedade. Fundação Calouste Gulbenkian. Lisboa: 2004.

FLUSSER, Vilém. Comunicologia: reflexões sobre o futuro: as conferências de Bochum. São Paulo: Martins Fontes, 2014.

FLUSSER, Vilém. Filosofia da caixa preta: ensaios para uma futura filosofia da fotografia. São Paulo: Annablume, 2011.

FLUSSER, Vilém. O mundo codificado: por uma filosofia do design e da comunicação. São Paulo: Cosac Naify, 2007.

FLUSSER, Vilém. A escrita - Há futuro para a escrita? São Paulo: Annablume, 2010.

FLUSSER, Vilém. Ser judeu. São Paulo: Annablume, 2014.

FLUSSER, Vilém. Fenomenologia do brasileiro. Rio de janeiro: Eduerj, 1998.

FLUSSER. Vilém. Língua e realidade. São Paulo: Annablume, 2004.

FLUSSER. Vilém. Ficções filosóficas. São Paulo: Editora da Universidade de São Paulo, 1998.

\section{Endereço postal:}

Programa de Pós-Graduação em Filosofia da PUCRS

Av.Ipiranga 6681, Porto Alegre - RS, Brasil

Data de recebimento: 11/04/2018

Data de aceite: 17/09/2018 